\title{
Ethical issues with colorectal cancer screening-a systematic review
}

\section{Bjørn Hofmann $\mathrm{PhD}^{1,2}$}

${ }^{1}$ Professor of Medical Ethics, The Centre of Medical Ethics at the University of Oslo

${ }^{2}$ Department of Health Science, Norwegian University for Science and Technology, Gjøvik, Norway

Correspondence

Bjørn Hofmann, Centre for Medical Ethics, University of Oslo, PO Box 1130, Blindern, N-0318 Oslo, Norway.

Email: b.m.hofmann@medisin.uio.no

the potential to harm through risks of the procedure itself, false test results, unnecessary detection, and treatment, as well as anxiety or

Colorectal cancer (CRC) is among the most frequently occurring malignant tumors and the leading cause of cancer-related death in Europe and the United States of America. The CRC screening is recommended by a wide range of professional organizations, national bodies, and international communities. ${ }^{1-3}$ By now screening is introduced in many countries, in several countries before high-quality evidence on outcomes was available. The CRC screening is characterized by many available screening strategies with distinct features, advantages, and downsides making assessment (and implementation) challenging. As with all screening programs, not all individuals participating will personally benefit from participation, and screening programs have health reassurance and lowered self-care.

There are many HTAs on CRC screening, but assessment of ethical, social, and legal aspects of health promotion and disease prevention activities is often lacking. ${ }^{4}$ A recent article presents and discusses some of the ethical issues in CRC screening. ${ }^{5}$ This article provides an extended and a more elaborate review.

Accordingly, the aim of this article is to expose and elucidate relevant ethical issues in the literature on CRC that are important for open and transparent deliberation on CRC screening. The article does not differentiate between ethical aspects that are important for the decision on whether to implement CRC screening and aspects that 
are important when (not) implementing screening. The reason for this is that it may be difficult to differentiate between the aspects and because both types of aspects are important for decision makers.

The CRC screening involves several stakeholders. Screening is aimed at healthy persons in specific age groups, normally within the age of 50 to 75 years. Relatives may become involved in the case of genetic determinants of CRC. Health professionals and industry is involved, as are health policy makers.

Moreover, several approaches are used for CRC. The most commonly used methods are colonoscopy, sigmoidoscopy, and fecal occult blood test (either guiac based, gFOBT, or with immunological detection of humane blood, iFOBT). Hence, there are significant differences between the approaches for CRC screening (intervention).

\section{2 | METHODS}

An axiological question-based (Socratic) approach for ethics in HTA was applied to identify ethical issues relevant for decision makers. ${ }^{6} \mathrm{~A}$ literature search was performed to identify relevant ethical issues. ${ }^{7,8}$ The search strategy was informed by stakeholder meetings and was elaborated from a list of 33 questions of the Socratic approach and is described in detail in Appendix 1. The specific searches were performed in the following databases: MEDLINE, Embase, PsycINFO, PubMed Bioethics subset, ISI Web of Knowledge, Bioethics Literature Database (BELIT), Ethics in Medicine (ETHMED), SIBIL Base dati di bioetica, LEWI Bibliographic Database on Ethics in the Sciences and Humanities, and EUROETHICS. Search strategies were elaborated for each database, because of the differences in content, indexing, and search options. For the searches in MEDLINE and Embase the same search strategy for "colorectal cancer» and «screening» were applied as for a recent systematic review by Fretheim et al. ${ }^{9}$

All titles, abstracts, and keywords of the identified references were investigated with respect to relevance to the various questions of the approach. References addressing ethical issues were examined full text, and ethical issues, concerns, considerations, and arguments were included. Identified ethical issues were analyzed by a researcher trained in HTA and ethics and grouped in accordance with their content. Identified issues that were not addressed by any questions were highlighted, and questions not covered by any identified issues were scrutinized with supplementary searches to see if there are ethical issues that have not been identified by the literature. These supplementary efforts are based on training in ethics.

As the approach aims at comprehensiveness in covering all ethical issues, and not at exhaustiveness in identifying all references addressing the same issue, only seminal references were included for the same issue. References only mentioning that there are ethical issues without providing any substance or analysis of the issue(s) were excluded.

\section{3 | RESULTS}

57 F1 The results from the literature search are illustrated in Figure 1.

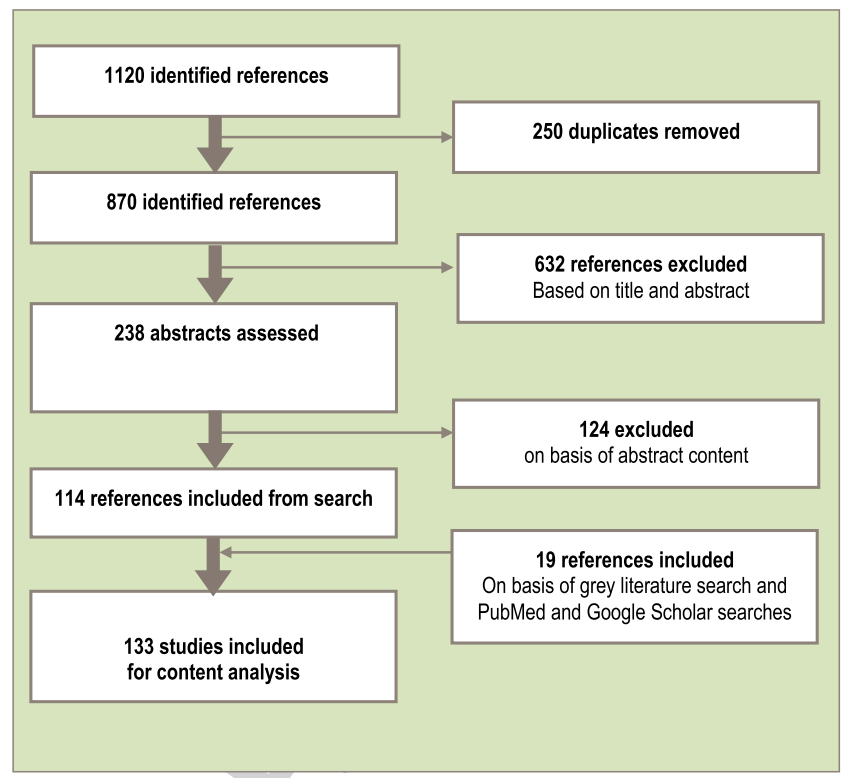

FIGURE 1 Flowchart over results from literature search

\section{1 | Benefits, burdens, and harms}

The CRC is a type of cancer that develops relatively slow and thus is well suited for screening. Benefits and harm will depend on uptake, skills, and organizing of screening program, ie, on context. One such contextual evidence compilation (for Norway) is shown in Table 1. T None of the methods has demonstrated a reduction in the overall mortality rate. ${ }^{9}$ False reassurance due to screening is suggested as one reason for the discrepancy between reduction in relative and absolute mortality rate ${ }^{10-12}$ and that screening "does not actually save lives but shifts individuals to other causes of mortality" is another. ${ }^{5,13}$

\section{2 | Benefits}

The main benefits are identified as reduced CRC mortality and reduced disease incidence (for sigmoidoscopy). Table 1 shows the estimated number of deaths avoided. In addition, some may also experience reduced anxiety and health reassurance, resulting from CRC screening. ${ }^{14}$ Endoscopic screening also avoids some of the challenges with other screening programs, such as anxiety, because detection, diagnosis, and treatment can be delivered at the same time. ${ }^{15}$

The benefits have made several international and national organizations to recommend CRC screening, which is considered by many to be an ethical imperative. ${ }^{16}$

\section{3 | Harms}

As seen in Table 1, bleeding, perforation, and death are potential harms, resulting from (subsequent) endoscopic procedures. Severe bleeding resulting from (subsequent) colonoscopy is observed in $0 \%$ to $0.2 \%$ of patients. ${ }^{17}$ The risk of death is estimated to be $0.002 \%$ for colonoscopy. ${ }^{9}$

Other identified harms are false test results (negative and positive), overdetection, overdiagnosis, overtreatment, and adverse effects of such diagnostics and treatment. False positive test results generate a risk of people having to undergo unnecessary diagnostic 
tests and may generate worries of having a disease that is not pres-

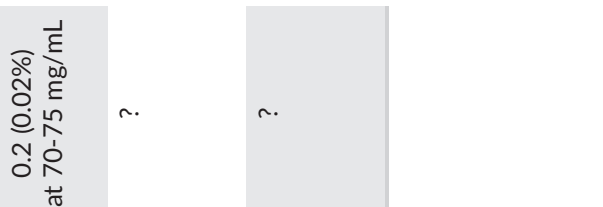

ent ${ }^{18}$ and can result in reduced adherence. ${ }^{19}$ False-negative test results can give rise to false reassurance and thereby possible ignorance of future symptoms of cancer, ultimately resulting in delayed diagnosis ${ }^{20}$ and poorer outcomes.

Overdiagnosis is rarely assessed. Only 1 study has assessed overdiagnosis for early detection in CRC screening and estimated an overdiagnosis rate of $0.1 \%$ to $0.9 \%{ }^{21}$ The reason for this may be that the main focus has been prevention and not early detection and the definition of overdiagnosis. By only including manifest CRC in the definition of overdiagnosis, the numbers will be small. However, if one would include all polyps acted on (which would not evolve to manifest $\mathrm{CRC}$ ) the overdiagnosis rates would be much higher.

Prevention CRC screening aims at identifying and removing precursors of disease. However, most resected colonic polyps would not have otherwise caused morbidity or death as they would not advance to disease, and many of them would regress. ${ }^{22}$ Identification and removal of such lesions represents overdetection and overtreatment, respectively, and the overdetection ("overreporting" and "oversurveillance") and overtreatment rate is substantial as most of the identified lesions would not have developed to CRC if they were not detected, and the trend is to find ever smaller lesions. ${ }^{23}$ However, polypectomy is considered to be far less invasive and cumbersome than the treatment of cancer and therefore considered to be less morally challenging. ${ }^{5}$ Nonetheless, it has been pointed out that CRC screening can inflict psychological distress on persons screened and be a source of targe costs and resources. ${ }^{5}$ However, no calculations of such costs have been identified. The detection and removal rate of nonadvanced adenomas is strongly increasing. ${ }^{23}$ While this is done to decrease the number of interval cancers and the CRC mortality rate, it comes at the cost of a substantial increase in unnecessary detection and removal of adenomas. Hence, overuse and underuse have been identified ${ }^{24}$ as moral problems, and it has been argued that improved survival is associated with improvement in treatment as much as with early detection. ${ }^{25}$

The main burdens are related to (endoscopic) examinations. Moderate or severe abdominal pain after colonoscopy are reported to be common for persons examined with standard air insufflation (16.6\%) and less so with carbon dioxide (CO2) insufflation (4\%). ${ }^{17}$

There has also been a worry about CRC screening having a negative effect on lifestyle in general, ${ }^{11,26,27}$ because of health reassurance. On the other hand, it has been pointed out that information about CRC and screening can cause anxiety, ${ }^{28}$ and anxiety with test results is reported. ${ }^{29}$

\section{4 | Benefits versus harms}

Benefits and harms are core factors for a utilitarian analysis together with costs. Costs will vary from country to country. A recent Norwegian cost-effectiveness analysis of CRC screening at the age of 55 shows that the incremental cost-effectiveness ratio (ICER) was estimated to be 12930 USD/QALY for sigmoidoscopy for men and 17443 USD/QALY for women in a health services perspective. For iFOBT and colonoscopy the numbers are based on 
additional assumptions as high-quality study results are not ready yet. For iFOBT the ICER is estimated to be 31224 USD/QALY for men and 23799 USD/QALY for women (biannually, 10 rounds). For colonoscopy the ICER is estimated to be 18097 USD/QALY for men and 24077 USD/QALY for women. ${ }^{30}$

Balancing benefits and harms is identified as one of the major ethical challenges with screening in general and CRC screening in particular. ${ }^{31}$ One reason may be that lead time and length time bias may make assessment of benefits and risks demanding. ${ }^{5}$ Another is that harm and risk may vary with comorbidity and medication (eg, blood thinners). Moreover, persons may balance benefits and burdens differently, eg, health care professionals and patients may value true positives and false positives differently. ${ }^{32}$

Assessing outcomes for various screening strategies is also difficult because of complexity, ${ }^{33}$ eg, using a noninvasive initial screening test (gFOBT or iFOBT) may increase uptake but increase anxiety and decrease efficiency. The same goes for the apparently technical question of setting cut-off values. ${ }^{34}$ All these issues make it a complex matter balancing benefits and harms.

\section{5 | Uptake}

Uptake varies greatly with screening method ${ }^{35}$ with sex, ${ }^{36}$ ethnic group, ${ }^{37,38}$ religiosity, ${ }^{39}$ distance to facility, ${ }^{40}$ and country. Uptake varies from $58 \%$ to $90 \%$ in high-quality studies on outcome. ${ }^{9}$ There is considerable variation in CRC screening by sociodemographic characteristics, ${ }^{34,41}$ by information provided, ${ }^{42,43}$ by the provider's understanding of patient's social context, ${ }^{44}$ and also by different world view, eg, fatalism (the view that all events are subject to fate or are inevitable). ${ }^{45}$ Moreover, high-risk groups may have lower participation rates. ${ }^{46-48}$ All such circumstances may result in selection bias in outcome studies.

Maintaining participation throughout successive screening invitations is identified as a core challenge. ${ }^{34,49}$ Uptake extensively depends on trust, which is a cherished but delicate value in health care.

Uptake is also related to questions of autonomy and consent. Historically, beneficence has trumped autonomy to increase the uptake and hence the outcome of a screening program. Even today, it is acknowledged that increasing uptake, and hence, population health is a multifaceted and difficult task. ${ }^{50}$

\section{6 | Autonomy, information, and consent}

Respecting people's autonomy and obtaining real-expressed informed consent are identified as some of the major ethical challenges with CRC screening. ${ }^{31,51}$ In this information about risks and benefits in a balanced manner is challenging. ${ }^{52}$ Studies also show that adults want full information on risks and benefits of screening while they also want a recommendation from an authoritative source. ${ }^{53}$ Emotional aspects and friends' subjective norms tend also to be very important for decisions to participate and to adherence. ${ }^{54}$ Factors other than provision of information appear to determine people's CRC screening preferences, ${ }^{46,55}$ especially for older people. ${ }^{56,57}$

The very different characteristics of the various screening tests prompt the question of whether invitees should be able to choose which screening method they find most appropriate according to their preferences. ${ }^{58,59}$ Choice of CRC screening method varies. One large study found that patients who were offered an informed choice for screening had higher adherence rates than patients who were not offered a choice of screening test. ${ }^{60}$ On the other hand, a minority of persons being screened report to have been asked about their preferences, ${ }^{61}$ and preferences tend to vary. ${ }^{62}$

Knowledge of CRC screening is also very variable, ${ }^{63}$ and a great number of invited persons do not make informed decisions about screening. ${ }^{64}$ Information may overstate benefits ${ }^{65}$ probably to increase uptake. $^{5}$ Accordingly, the quality of informed consent has been demonstrated to be low. ${ }^{66}$ Nonetheless, people tend to want to be informed about risks. ${ }^{67}$

Informed decision making may reduce the participation in screening. ${ }^{68,69}$ Therefore, nudging and biased information has been suggested for CRC surveillance, ${ }^{70}$ and also for screening. ${ }^{71}$ Ways to try to counterbalance "optimistic bias" have also been suggested (see below). ${ }^{72}$ However, nudging and biased information is controversial as it breaches with standard conceptions of the principle of autonomy. Correspondingly, incentives may increase uptake of CRC screening, ${ }^{73}$ but has been rejected on moral grounds. ${ }^{74}$

Providing balanced information has been identified as a substantial challenge. ${ }^{75,76}$ One of the reasons for the challenges with informing about CRC screening is the (previously mentioned) complexity, and because it is hard to relate populational data to individuals and because of what has been called the "prevention paradox," ie, that although the screening will be of significant benefit to the population as a whole the individual's decision to get screened regularly may only have a small impact on that individual's risk of disease in the near future. ${ }^{77}$ Even personalized quantitative CRC risk information is shown to have different effects on individuals, ${ }^{78}$ making personal targeting difficult. Moreover, enthusiasm has spurred-biased information. ${ }^{79}$

Accordingly, there may be many barriers to making informed choice, both personal (for potential participants) ${ }^{57}$ and professional. ${ }^{80}$ Crucial information is not always available, such as on overdiagnosis (early detection) and number of polyps detected and removed without benefit (overdetection and overtreatment with preventive screening). Moreover, for screening programs with initial noninvasive screening tests information about subsequent invasive tests may reduce uptake, posing an ethical dilemma. ${ }^{81}$ Another challenge is that people typically believe their health risks are lower than those of others (ie, optimistic bias). ${ }^{82}$ Yet another psychological effect is defensive information processing about CRC screening. ${ }^{83}$

A wide range of measures to improve information to participants and increase informed consent have been suggested and tested. ${ }^{65,72,84-91}$ These may cause dilemmas of their own, for example, targeting information to African Americans implies the risk of making people aware of disparities and disadvantages. ${ }^{92}$ Lack of awareness and misconceptions are identified as reasons for lack of outcome from actions against $\mathrm{CRC}{ }^{93}$ As information may result in anxiety ${ }^{28}$ or "cancer information overload," this poses a moral dilemma. However, ways of informing may reduce the risk of anxiety and overload, and contextual sensitivity appears to be important. ${ }^{94}$ On the other hand, some persons view participation as accepting an offer, where being informed does not impact on participation rates. ${ }^{51}$ Moreover, different 
groups may have very different needs for information, ${ }^{95,96}$ and it can be difficult to predict their information preferences. ${ }^{97}$

Hence, providing relevant information may be challenging and resource demanding. ${ }^{98}$ Knowledge about the efficiency of the various methods for promoting informed consent is limited, and no one method appears to stand out in efficiency. ${ }^{84,99}$

\section{7 | Practical challenges with screening-ethical implications}

Due to the many options, optimizing screening strategies is identified as a chief challenge. ${ }^{34}$ Tailoring the frequency of screening and limiting intervention for polyps that are not believed to be precursors to morbid disease have been key practical challenges with moral connotations. $^{22}$ So is providing risk-based personalized screening. ${ }^{100}$

How to assess and balance the various CRC screening strategies is demanding. Evidence for gFOBT and sigmoidoscopy is available, while we still have to wait many years for high-quality results from comparative studies with iFOBT and colonoscopy. ${ }^{9}$ Whether one should introduce CRC screening programs with one or more of the tests where high-quality evidence is available, or whether to introduce alternative promising screening strategies on the basis of preliminary evidence (and modeling), or whether to set up screening programs as (long lasting and costly) scientific studies poses significant moral quandary. In the latter case, also which design to use and which screening tests to include. Moreover, offering gFOBT as one of the arms in a study could breach the criteria for equipoise (in research ethics).

Other practical issues, such as specific staffing, financial, and training $^{101}$ may also have moral implications ${ }^{102}$ as well as unreachable referred patients and medical ineligibility (eg, symptomatic comorbid conditions) $)^{103}$ as target group may not be reached as intended. Such complexities of screening programs and a range of organizational challenges have been discussed, ${ }^{104-108} \mathrm{eg}$, how to coordinate screening centers with ordinary clinical activities, and ignoring such challenges may result in suboptimal implementation.

Moreover, timing of implementation is a major concern, as CRC screening programs are resource demanding and take time to roll out. As some methods are easier to implement than others, they could provide screening to greater parts of the population faster. Implementing what is presently considered to be the best screening test may exclude many from being screened (because of timing issues), and the test may turn out to be inferior when the program is fully implemented.

How to communicate screening results in a gentle, correct, and comprehensive manner is also a challenge. ${ }^{109}$ Yet another issue that follows from implementing screening is what to do regarding assessing the risk of family members of persons identified with CRC by screening. Some clinicians have pointed out that this represents a pertinent moral dilemma, as they think that all family members of persons with CRC should be screened, while they do not take the time to do so. ${ }^{110}$ On the other hand, contacting family members' conflict with the right to privacy and the right not to know.

Due to a potential "health certificate effect" in CRC screening (where a test functions as a certificate of being healthy and having a negative effects on health awareness and lifestyle changes) there may be a need for extensive participant education. ${ }^{10,11}$ Moreover, tailored advice given in the context of cancer screening may provide an opportunity to improve dietary behaviors. ${ }^{111}$

\section{8 | Equity and equal access}

Due to geographical variations between and within several countries, the access to screening (and uptake) may vary, and disparities in CRC screening have been identified. ${ }^{112-119}$ For example, a strong interphysician variation and intercenter variation in the adenoma detection rate has been demonstrated, even after adjustment for patient factors. ${ }^{23}$ Discrepancies in lifestyle have been illustrated, where people being more physically active were more likely to participate. ${ }^{120}$ Disparities with respect to race/ethnicity are identified. ${ }^{121-124}$ Persons with mobility disabilities are less likely to access cancer screening. ${ }^{125}$ Reduced health literacy may also generate differences in uptake ${ }^{126-128}$ and access to screening, eg, web sites providing information may be too difficult for the average (American) adult and much too difficult for adults with limited literacy ${ }^{129}$ or cognitive capacity. ${ }^{130}$ While making an informed decision about participation in CRC screening may be challenging for invitees with lower health literacy skills, the association between health literacy and informed decision making is complex. ${ }^{131}$ Some groups have also shown higher rates of false test results. ${ }^{132}$

Hence, reaching the underserved remains a core challenge. ${ }^{34}$ Various measures to reach underserved groups have been suggested, ${ }^{49}$ but some may conflict with ethical principles, such as respect for autonomy.

Additionally, adherence to screening guidelines is varying, ${ }^{133-135}$ probably also because of more or less reflected professional disagreement or perspectives. ${ }^{41,136,137}$ Cost-effectiveness information appears to have little influence on physicians' cancer screening recommendations. ${ }^{138}$

Accordingly, equity and equal access are important moral issues. So is the question of how to balance equity and efficiency. Some studies show that equity trumps efficiency, ${ }^{139}$ ie, that equal access to screening with respect to sex and age is considered to be more important than to select those groups where screening is most efficient (independent of sex and age).

\section{9 | Justice}

Studies show less effect of CRC screening with women. ${ }^{140,141}$ This raises the question of how to provide just screening programs for men and women. The same challenge exists for age, as the number of polyps increase significantly at the age 55 to 70 while CRC incidence increases at age 65 to 70 . This makes it challenging to set lower and upper age limit. ${ }^{142,143}$ At the same time, screening risks may increase for older persons, ${ }^{144,145}$ while the capacity to adhere to test preparations may decrease ${ }^{146}$ and to consent may decrease in older persons. However, whether age is a selection criterion is contested. ${ }^{147,148}$

Various groups may also differ significantly in risk, ${ }^{100,149}$ and there are differences in how various groups experience burdens of endoscopy. "Mathematically just" may appear "emotionally unjust" in the 
population. Hence, which group to offer screening (and where to set limits, eg, to age and cut-offs) poses significant ethical challenges which are important for decision makers and health policy makers implementing screening programs. On the other hand, CRC does not have a social gradient and is not suitable for evening the playing field, ${ }^{150}$ ie, to reduce the differences in health.

If screening programs drain resources from cancer surveillance and treatment it may pose ethical challenges (with respect to priority setting). This is especially problematic for high rates of overdetection and overuse. Another identified issue is that insurance companies may restrict insurance or increase insurance premium, as a positive test result may indicate an increased risk of disease. ${ }^{151}$

At a more general level, whether it is right to use resources on health services for many healthy people for a condition that only relevant for a small fraction of the population (4\%), ${ }^{24,150}$ where there is a significant delay before results are experienced (10-15 years), ${ }^{152}$ and where there is no overall reduction of mortality, while relevant alternatives exist ${ }^{153}$ is a key moral question.

\subsection{0 | The ethics of evidence and action}

Evidence does not dictate implementation. Despite evidence and recommendations, several countries have not implemented screening. ${ }^{154-156}$ On the other hand, some types of screening have been implemented without high-quality evidence, eg, with iFOBT and colonoscopy. Although such decisions may be based on accuracy data and modeling studies, making it "unethical not to screen," it can become difficult to obtain evidence on these screening strategies in the future. ${ }^{5}$

\subsection{1 | Altering conceptions of disease}

One important question that was not addressed in the literature is the status and prestige of the disease and the means to prevent, detect, and treat it. The CRC is organ specific and can be detected with advanced technology. Accordingly, it has a high prestige to physicians. ${ }^{157}$ Cancer also has a special position among diseases. ${ }^{158}$ Screening changes the attention on and the conception of a disease. It also alters the end of health care services, from avoiding death because of CRC to avoid development of tumors. ${ }^{159}$ Therefore, screening against CRC may well increase its status.

Polyps are very frequent in the (older people) population, and they normally do not result in symptoms, disease, or death. With screening they become target of medical attention and treatment, ie, making them disease (protodisease and psudodisease). Previously serrated lesion of the colorectum were not considered to be significant, but are now considered to be precancers (preconditions for cancers). ${ }^{160,161}$ Making polyps subject to medical attention has been criticized for being a kind of medicalization. ${ }^{162}$ Invitation to screening may also result in worries and in people seeing themselves as patients, ${ }^{163}$ ie, changing their selfconception and contributing to the medicalization of ordinary phenomena. Also, as people who remove polyps/adenomas are followed up they become patients (every 1,3 , or 10 years).

Moreover, removal of premalignant conditions may be conceived of as a form of human enhancement and promote an ideal image of a human being. This may pave the way for other types of enhancements: "we improve human beings by removing (normal) polyps $(X)$, so why should we not improve human beings by doing Y?" This mode of reasoning is frequently referred to as "the slippery slope argument" and is somewhat controversial. ${ }^{164,165}$

Having and removing polyps may alse change persons' selfconception, eg, their vulnerability on the one hand and their improved health status on the other ("the health certificate effect"). Moreover, a safety net of screening may also make people expose themselves to risks, ie, "moral hazard."12 Hence, screening programs and conceptions of cancer may change conceptions of self and alter our ways of communicating. ${ }^{119}$

\subsection{A rose by any other name?}

As CRC screening focuses on polyps, it appears to be important what the screening program is called. Calling it a "CRC screening program" only covers the detection part of screening and would be misleading. Calling it a cancer prevention screening program may be more formally correct, but people would probably think that it detects cancers early. Calling it a "polyp resection program" would be more correct, but would probably not promote a high uptake. Hence, the name is more than a formality, as the choice will determine the measures for the benefits and the harms. A polyp resection program may have zero (cancer) overdiagnosis, as (almost) no cancer diagnosis is made. Polyps are detected and resected. However, a CRC screening program may have significant overdiagnosis, contrary to what it is considered to be today. $^{21}$

\subsection{3 | Some legal aspects}

It has been pointed out in the literature that introducing screening legislation has been shown not to have any clear impact on disease incidence (in reduction) ${ }^{166}$ and that CRC screening touches on legal provisions regarding confidentiality of patients and other human rights issues. $^{151}$

\subsection{4 | Cut-offs and incidental findings}

One of the identified challenges is to decide on cut-off values, ${ }^{34,167}$ eg, for polyp size. Removing very-low-risk polyps at a small, but real risk may be morally challenging.

A related problem is return of incidental findings. Several of the methods may find other health-related problems, and how to handle these may result in moral dilemmas.

\section{4 | DISCUSSION}

This review has identified a wide range of ethical issues. Some are related to basic ethical principles, such as autonomy, beneficence, nonmaleficence, and justice while others connect to basic concepts for health care, such as disease. Yet others connect to societal aspects, such as medicalization and overtreatment.

It is difficult to stop screening when you have started, and disinvestments are hard to make. ${ }^{168,169}$ Hence, thorough assessment 
appears to be warranted. It may be possible to state specific aims, and if these aims are not achieved in a given time frame, the program will be terminated.

Although some ethical issues are extensively discussed in the literature, such as informed consent, it does not necessarily mean that informed consent is a particularly challenging issue with CRC screening, as the many references may stem from informed consent has obtained much attention in general.

A wide range of relevant related issues have not been addressed in this review, eg, issues specific to emerging (biomarker or imaging) tests for CRC and the relationship between CRC and other (genetic) diseases, such as Lynch syndrome. Although such issues obviously raise a series of ethically relevant questions, they are beyond the scope of this review.

Some issues appear rather technical, eg, whether to assess and inform about screening programs on the basis of relative or absolute CRC risk reduction. ${ }^{170,171}$ However, such questions have strong moral bearings, which it is important to acknowledge to facilitate an open and transparent deliberation. Informing the public that CRC screening reduces mortality (in general) may be misleading. ${ }^{79}$

Most of the identified ethical issues are covered by the questions of the axiological method, ${ }^{6}$ but not all, eg, some of the practical challenges are not explicitly included in the questions. Moreover, several of the questions address issues not found in the literature, eg, whether it affects religious convictions, and whether screening would increase the status and prestige of the disease. Other methods for addressing ethical issues ${ }^{172}$ could of course have been applied. However, this review has identified a series of other ethical issues than previous studies ${ }^{5}$ and is in line with other studies on ethics in screening. ${ }^{31,173}$

From exposing and elucidating the relevant ethical issues one would ask for specific recommendations. Should we implement CRC screening, or not? If yes, what kind of screening program? As these questions have to be answered in context, this review only provides input for the contextual decision-making process. In the same manner as evidence does not dictate implementation, ${ }^{154-156}$ neither does a review of the ethical issues, ie, there is no ethical "imperative of evidence." Nonetheless, the review can prepare and facilitate this process.

\section{5 | CONCLUSION}

This review has identified a wide range of important ethical issues. First and foremost, it has revealed how complex CRC screening is and how difficult this makes a utilitarian analysis of benefits and harms. While predictive CRC screening poses problems with false test results and overdiagnosis, preventive screening proffers problems with overdetection and overtreatment. All screening presents potential harms because of the procedures, such as bleeding, perforation, and (seldom) death. These issues have to be balanced against the benefits of screening, such as reduced relative mortality and incidence rate.

Moreover, the question of participants' choice (autonomy) emerges as important. So do challenges with informing about screening in a manner that promotes and assures informed choice and at the same time reinforces uptake. Assuring equal access, equity in uptake, and justice surface as important ethical issues, eg, in the question of which groups should be offered which screening (age, sex, and risk class). Reaching the underserved is a core issue.

Societal issues, such as medicalization of ordinary conditions, changing the conception of disease, medicalization, and paving the way for enhancement, are also relevant.

In utilitarian terms the crucial moral question is whether it is right to perform 5700 colonoscopies, of which 11 will have their colon perforated, 914 will have moderate or severe abdominal pain, 2860 will have polyps removed unnecessarily, and 0 to 1 will die, to prevent 157 to die from CRC for every 100000 persons invited, without reducing the overall mortality rate.

\section{ACKNOWLEDGMENTS}

I am most thankful for input from active participants at a stakeholder meeting at the Directorate of Health in Oslo May 27 and at The Norwegian Cancer Registry in Oslo June 6, 2016, as well as to research librarian Ingvild Kirkehei at the Norwegian Institute for Public Health for help with the search. I am also very thankful to The National Council for Priority Setting in the Health Care for funding part of this study.

\section{REFERENCES}

1. Commission of the European Communities. Council Recommendation on Cancer Screening. Brussels: European Commission; 2003.

2. Sung JJY, Lau JYW, Young GP, et al. Asia Pacific consensus recommendations for colorectal cancer screening. Gut. 2008;57(8):1166-1176.

3. Smith RA, Brooks D, Cokkinides V, Saslow D, Brawley OW. Cancer screening in the United States, 2013: a review of current American Cancer Society guidelines, current issues in cancer screening, and new guidance on cervical cancer screening and lung cancer screening. CA Cancer J Clin. 2013;63(2):88-105.

4. Banta HD, Hatziandreu E, Dauben HP, et al. Health promotion and disease prevention as a complement to community health indicators: Working group 1. Int J Technol Assess Health Care. 2002;18(2):238-272.

5. van Dam L, Bretthauer M. Ethical issues in colorectal cancer screening. Baillieres Best Pract Res Clin Gastroenterol. 2014;28(2):315-326.

6. Hofmann B, Droste S, Oortwijn W, Cleemput I, Sacchini D. Harmonization of ethics in health technology assessment: a revision of the Socratic approach. Int J Technol Assess Health Care. 2014;30(1):3-9.

7. Droste S, Dintsios C-M, Gerber A. Information on ethical issues in health technology assessment: how and where to find them. Int J Technol Assess Health Care. 2010;26(04):441-449.

8. Lysdahl K, Droste S. Ethical analysis. 2016. Available at http://vortal. Q6101 htai.org/?q=node/11. Accessed August 8, 2016.

9. Fretheim A, Reinar L, Bretthauer M. Health Effects of Colorectal Cancer Screening. Oslo: Norwegian Institute of Public Health; September 1, 2016.

10. Larsen IK, Grotmol T, Almendingen K, Hoff G. Impact of colorectal cancer screening on future lifestyle choices: a three-year randomized controlled trial. Clin Gastroenterol Hepatol. 2007;5(4):477-483.

11. Berstad $\mathrm{P}$, Loberg $\mathrm{M}$, Larsen IK, et al. Long-term lifestyle changes after colorectal cancer screening: randomised controlled trial. Gut. 2015;64(8):1268-1276.

12. Eisinger F, Morere JF, Touboul C, et al. Vulnerable populations and overconfidence in cancer screening. Journal of Clinical Oncology Conference. 2014;32(15 SUPPL. 1).

13. Gates TJ. Screening for cancer: evaluating the evidence. Am Fam Physician. 2001;63(3):513-522. 
14. Emanuel AS, Kiviniemi MT, Howell JL, et al. Avoiding cancer risk information. Soc Sci Med. 2015;147:113-120.

15. Laurance J. Ignorance can be preferable? Lancet. 2010;375(9732):2138.

16. Braillon A. Colorectal cancer screening, ethics and evidence-based public policy. J Med Screen. 2011;18(2):103 author reply 103-104.

17. Bretthauer M, Kaminski MF, Loberg M, et al. Population-based colonoscopy screening for colorectal cancer: a randomized clinical trial. JAMA Intern Med. 2016;176(7):894-902.

18. van der Velde JL, Blanker MH, Berger MY, Berendsen AJ. The impact of a false-positive colorectal cancer-screening test on quality of life: a systematic review. Eur J Cancer Care (Engl). 2015;24:33-33.

19. Taylor KL, Shelby R, Gelmann E, McGuire C. Quality of life and trial adherence among participants in the prostate, lung, colorectal, and ovarian cancer screening trial. J Natl Cancer Inst. 2004;96(14):1083-1094.

20. Gillberg A, Ericsson E, Granstrom F, Olsson LI. A population-based audit of the clinical use of faecal occult blood testing in primary care for colorectal cancer. Colorectal Dis. 2012;14(9):e539-e546.

21. Brenner H, Altenhofen L, Stock C, Hoffmeister M. Prevention, early detection, and overdiagnosis of colorectal cancer within 10 years of screening colonoscopy in Germany. Clin Gastroenterol Hepatol. 2015;13(4):717-723.

22. Shieh Y, Eklund M, Sawaya GF, Black WC, Kramer BS, Esserman LJ. Population-based screening for cancer: hope and hype. Nat Rev Clin Oncol. 2016;13:13.

23. Brenner $\mathrm{H}$, Altenhofen L, Kretschmann J, et al. Trends in adenoma detection rates during the First 10 years of the German screening colonoscopy program. Gastroenterology. 2015;149(2):356-366. e351.

24. Garcia M. Addressing overuse and overdiagnosis in colorectal cancer screening for average-risk individuals. Colorectal cancer. 2015;4(1):27-35.

25. Lopez-Bastida J, Bellas-Beceiro B, Quintero-Carrion E. The challenge of colorectal cancer prevention in Spain. Eur J Health Econ. 2010;10(Suppl 1):S75-S83.

26. Jantti M, Heinavaara S, Helander S, Sarkeala T, Malila N. Respondent selection in a repeated survey on lifestyle within the randomized colorectal cancer screening programme. Eur J Cancer Prev. 2016;10:10.

27. Deutekom M, Vansenne F, McCaffery K, Essink-Bot ML, Stronks K, Bossuyt PM. The effects of screening on health behaviour: a summary of the results of randomized controlled trials. J Public Health (Oxf). 2011;33(1):71-79.

28. Robb KA, Miles A, Campbell J, Evans P, Wardle J. Can cancer risk information raise awareness without increasing anxiety? A randomized trial. Preventive Medicine: An International Journal Devoted to Practice and Theory. 2006;43(3):187-190.

29. Pruyn J, Wvd H. Anxiety, control, and information-seeking behavior in screening for cancer. In: Stress and anxiety, Vol 11. New York, NY: Hemisphere Publishing Corp/Harper \& Row Publishers, US; 1988:183-195.

30. Aas E. Analyses of Costs and Cost-Effectiveness for Various Screening Methods for Colorectal Cancer Screening [Analyser Av Kostnader Og Kostnadseffektivitet Ved Ulike Screeningmetoder for Tarmkreft]. Helseøkonomisk Analyse AS: Oslo; 2016.

31. Ustun C, Ceber E. Ethical issues for cancer screenings-five countries -four types of cancer. Prev Med. 2004;39(2):223-229.

32. Boone D, Mallett S, Zhu S, et al. Patients' \& healthcare professionals' values regarding true- $\&$ false-positive diagnosis when colorectal cancer screening by CT colonography: discrete choice experiment. PLoS One. 2013;8(12):e80767.

33. Keighley M, Arnold R. Is colonoscopic screening of a low-risk (normal) population ethically justifiable? Dig Dis. 2002;20(3-4):246-252.

34. Halloran SP. Screening: Colorectal cancer screening-insights and challenges. Nat Rev Gastroenterol Hepatol. 2014;11(10):586-587.
35. Hol L, van Leerdam ME, van Ballegooijen M, et al. Screening for colorectal cancer: randomised trial comparing guaiac-based and immunochemical faecal occult blood testing and flexible sigmoidoscopy. Gut. 2010;59(1):62-68.

36. Friedemann-Sanchez G, Griffin JM, Partin MR. Gender differences in colorectal cancer screening barriers and information needs. Health Expectations: An International Journal of Public Participation in Health Care \& Health Policy. 2007;10(2):148-160.

37. Gwede CK, William CM, Thomas KB, et al. Exploring disparities and variability in perceptions and self-reported colorectal cancer screening among three ethnic subgroups of U.S. Blacks. Oncol Nurs Forum. 2010;37(5):581-589.

38. Crawford ND, Jones CP, Richardson LC. Understanding racial and ethnic disparities in colorectal cancer screening: behavioral risk factor surveillance system, 2002 and 2004. Ethn Dis. 2010;20(4):359-365.

39. Leyva B, Nguyen AB, Allen JD, Taplin SH, Moser RP. Is religiosity associated with cancer screening? Results from a national survey. J Relig Health. 2015;54(3):998-1013.

40. Rossi PG, Federici A, Bartolozzi F, Farchi S, Borgia P, Guasticchi G. Understanding non-compliance to colorectal cancer screening: a case control study, nested in a randomised trial ISRCTN83029072. BMC Public Health. 2005;5.

41. Buchman S, Rozmovits L, Glazier RH. Equity and practice issues in colorectal cancer screening Mixed-methods study. Can Fam Physician. 2016;62(4):E186-E193.

42. Shokar NK, Carlson CA, Weller SC. Informed decision making changes test preferences for colorectal cancer screening in a diverse population. Ann Fam Med. 2010;8(2):141-150.

43. Rimer BK, Briss PA, Zeller PK, Chan EC, Woolf SH. Informed decision making: what is its role in cancer screening? Cancer. 2004;101(5 Suppl):1214-1228.

44. De Jesus M, Puleo E, Shelton RC, McNeill LH, Emmons KM. Factors associated with colorectal cancer screening among a low-income, multiethnic, highly insured population: does provider's understanding of the patient's social context matter? Journal of Urban Health-Bulletin of the New York Academy of Medicine. 2010;87(2):236-243.

45. Powe BD. Fatalism among elderly African Americans. Effects on colorectal cancer screening. Cancer Nurs. 1995;18(5):385-392.

46. Blom J, Yin L, Liden A, et al. Toward understanding non participation in sigmoidoscopy screening for colorectal cancer. Int J Cancer. 2008;122(7):1618-1623.

47. Blom J, Yin L, Lidén A, et al. A 9-year follow-up study of participants and nonparticipants in sigmoidoscopy screening: importance of selfselection. Cancer Epidemiol Biomarkers Prev. 2008;17(5):1163-1168.

48. Senore C, Armaroli P, Silvani M, et al. Comparing different strategies for colorectal cancer screening in Italy: predictors of patients/' participation. Am J Gastroenterol. 2009;105(1):188-198.

49. Gupta S, Sussman DA, Doubeni CA, et al. Challenges and possible solutions to colorectal cancer screening for the underserved. J Natl Cancer Inst. 2014;106(4): dju032.

50. Hawley ST, Lafata JE. Colon cancer screening: tackling a multifaceted challenge. J Natl Cancer Inst. 2014;106(12):

51. Trevena L. Cancer screening-pros, cons, choice, and the patient. Aust Fam Physician. 2009;38(4):188-192.

52. Barrett $B$, McKenna P. Communicating benefits and risks of screening for prostate, colon, and breast cancer. Fam Med. 2011;43(4):248-253.

53. Waller J, Macedo A, von Wagner $\mathrm{C}$, et al. Communication about colorectal cancer screening in Britain: public preferences for an expert recommendation. Br J Cancer. 2012;107(12):1938-1943.

54. Honda K, Kagawa-Singer M. Cognitive mediators linking social support networks to colorectal cancer screening adherence. J Behav Med. 2006;29(5):449-460.

55. Jones RM, Devers KJ, Kuzel AJ, Woolf SH. Patient-reported barriers to colorectal cancer screening: a mixed-methods analysis. Am J Prev Med. 2010;38(5):508-516. 
56. Wolf AM, Schorling JB. Does informed consent alter elderly patients' preferences for colorectal cancer screening? Results of a randomized trial. J Gen Intern Med. 2000;15(1):24-30.

57. Jepson RG, Hewison J, Thompson A, Weller D. Patient perspectives on information and choice in cancer screening: a qualitative study in the UK. Soc Sci Med. 2007;65(5):890-899.

58. Madalinski M. Continuous quality improvement of colorectal cancer screening. World J Gastrointest Pharmacol Ther. 2013;4(1):1-3.

59. van Dam L, Kuipers EJ, Steyerberg EW, van Leerdam ME, de Beaufort ID. The price of autonomy: should we offer individuals a choice of colorectal cancer screening strategies? Lancet Oncol. 2013;14(1): e38-e46.

60. Wong MC, Ching JY, Chan VC, et al. Informed choice vs. no choice in colorectal cancer screening tests: a prospective cohort study in reallife screening practice. Am J Gastroenterol. 2014;109(7):1072-1079.

61. Zikmund-Fisher BJ, Couper MP, Singer E, et al. Deficits and variations in patients' experience with making 9 common medical decisions: the DECISIONS survey. Med Decis Making. 2010;30(5 Suppl):85s-95s.

62. Nayaradou M, Berchi C, Dejardin O, Launoy G. Eliciting population preferences for mass colorectal cancer screening organization. Med Decis Making. 2010;30(2):224-233.

63. Viguier J, Coscas Y, Touboul C, et al. Knowledge of the French population on colorectal cancer screening: Data from the EDIFICE 3 survey. Journal of Clinical Oncology. Conference. 2013;31:(4 SUPPL. 1)

64. de Haan MC, de Wijkerslooth TR, Stoop E, et al. Informed decisionmaking in colorectal cancer screening using colonoscopy or ctcolonography. Patient Educ Couns. 2013;91(3):318-325.

65. Miles A, Rodrigues $V$, Sevdalis N. The effect of information about false negative and false positive rates on people's attitudes towards colorectal cancer screening using faecal occult blood testing (FOBt). Patient Educ Couns. 2013;93(2):342-349.

66. Schwartz PH, Edenberg E, Barrett PR, Perkins SM, Meslin EM, Imperiale TF. Patient understanding of benefits, risks, and alternatives to screening colonoscopy. Fam Med. 2013;45(2):83-89.

67. Janssen N, Oort F, Fockens P, Willems D, de Haes H, Smets E. Under what conditions do patients want to be informed about their risk of a complication? A vignette study. Journal of Medical Ethics: Journal of the Institute of Medical Ethics. 2009;35(5):276-282.

68. Ling BS, Trauth JM, Fine MJ, et al. Informed decision-making and colorectal cancer screening: is it occurring in primary care? Med Care. 2008;46: (9Suppl1)S23-S29.

69. Smith SK, Trevena L, Simpson JM, Barratt A, Nutbeam D, McCaffery $\mathrm{KJ}$. A decision aid to support informed choices about bowel cancer screening among adults with low education: randomised controlled trial. BMJ (Clinical research ed). 2010;341:c5370.

70. Blumenthal-Barby JS, Cantor SB, Russell HV, Naik AD, Volk RJ. Decision aids: when 'nudging' patients to make a particular choice is more ethical than balanced, nondirective content. Health Aff (Millwood). 2013;32(2):303-310.

71. Purnell JQ, Thompson T, Kreuter MW, McBride TD. Behavioral economics: "nudging" underserved populations to be screened for cancer. Preventing Chronic Disease: Public Health Research, Practice, and Policy Vol 12 Jan 2015, ArtID 140346. 2015;12.

72. Lipkus IM, Klein WM. Effects of communicating social comparison information on risk perceptions for colorectal cancer. J Health Commun. 2006;11(4):391-407.

73. Aas E. Pecuniary compensation increases participation in screening for colorectal cancer. Health Econ. 2009;18(3):337-354.

74. Hagoel L, Rennert G, Feder-Bubis P. Laypersons' views of material incentives for enhancing colorectal cancer screening. Health Expect. 2015;18(5):1194-1203.

75. Smith SG, Vart G, Wolf MS, et al. How do people interpret information about colorectal cancer screening: observations from a think-aloud study. Health Expectations: An International Journal of Public Participation in Health Care \& Health Policy. 2015;18(5):703-714.
76. McQueen MJ. Some ethical and design challenges of screening programs and screening tests. Clin Chim Acta. 2002;315(1-2):41-48.

77. Rose G. Sick individuals and sick populations. Int J Epidemiol. 2001;30(3):427-432. discussion 433-424

78. Han PK, Duarte CW, Daggett S, et al. Effects of personalized colorectal cancer risk information on laypersons' interest in colorectal cancer screening: the importance of individual differences. Patient Educ Couns. 2015;98(10):1280-1286.

79. Meland E. Screening for kolorektal kreft [colorectal cancer screening]. Tidsskrift for den Norske laegeforening : tidsskrift for praktisk medicin, ny raekke. 2010;130(16):1598.

80. Wackerbarth SB, Tarasenko YN, Joyce JM, Haist SA. Physician colorectal cancer screening recommendations: an examination based on informed decision making. Patient Educ Couns. 2007;66(1):43-50.

81. Benning TM, Dellaert BG, Severens JL, Dirksen CD. The effect of presenting information about invasive follow-up testing on individuals' noninvasive colorectal cancer screening participation decision: results from a discrete choice experiment. Value Health. 2014;17(5):578-587.

82. Robb KA, Campbell J, Evans P, Miles A, Wardle J. Impact of risk information on perceived colorectal cancer risk: a randomized trial. $J$ Health Psychol. 2008;13(6):744-753.

83. McQueen A, Swank PR, Vernon SW. Examining patterns of association with defensive information processing about colorectal cancer screening. J Health Psychol. 2014;19(11):1443-1458.

84. Biesecker BB, Schwartz MD, Marteau TM. Enhancing informed choice to undergo health screening: a systematic review. Am J Health Behav. 2013;37(3):351-359.

85. Smith SG, Raine R, Obichere A, Wolf MS, Wardle J, von Wagner C. The effect of a supplementary ('gist-based') information leaflet on colorectal cancer knowledge and screening intention: a randomized controlled trial. J Behav Med. 2015;38(2):261-272.

86. Steckelberg A, Hulfenhaus C, Haastert B, Muhlhauser I. Effect of evidence based risk information on "informed choice" in colorectal cancer screening: Randomised controlled trial. BMJ: British Medical Journal. 2011;342(7810):1-7.

87. C-j L, Rawl SM. Effects of text cohesion on comprehension and retention of colorectal cancer screening information: a preliminary study. $J$ Health Commun. 2012; for 17(Suppl 3):222-240.

88. Marcus AC, Mason M, Wolfe $P$, et al. The efficacy of tailored print materials in promoting colorectal cancer screening: results from a randomized trial involving callers to the national cancer institute's cancer information service. J Health Commun. 2005; (10(Suppl1):83-104.

89. von Wagner C, Semmler C, Good A, Wardle J. Health literacy and selfefficacy for participating in colorectal cancer screening: the role of information processing. Patient Educ Couns. 2009;75(3):352-357.

90. Ledoux MT. Internet, physicians, and traditional mass media as health information sources for increasing colon cancer screening. Dissertation Abstracts International: Section B: The Sciences and Engineering. 2007;68(4-B) :2293.

91. Katz ML, Broder-Oldach B, Fisher JL, et al. Patient-provider discussions about colorectal cancer screening: who initiates elements of informed decision making? J Gen Intern Med. 2012;27(9):1135-1141.

92. Landrine $\mathrm{H}$, Corral I. Targeting cancer information to African Americans: the trouble with talking about disparities. J Health Commun. 2015;20(2):196-203.

93. Bayer TL. The effect of a health information intervention on perceptions regarding colorectal cancer. Dissertation Abstracts International: Section B: The Sciences and Engineering. 2008;69(3-B): 1563.

94. Nguyen GT, Bellamy SL. Cancer information seeking preferences and experiences: disparities between Asian Americans and whites in the health information national trends survey (hints). J Health Commun. 2006;11(Suppl1):173-180.

95. Orsi JM, Margellos-Anast H, Perlman TS, Giloth BE, Whitman S. Cancer screening knowledge, attitudes, and behaviors among culturally 
deaf adults: implications for informed decision making. Cancer Detect Prev. 2007;31(6):474-479.

96. Ellison J, Jandorf L, DuHamel K. Colonoscopy screening information preferences among urban Hispanics. J Immigr Minor Health. 2011;13(5):963-966.

97. Elkin EB, Kim SH, Casper ES, Kissane DW, Schrag D. Desire for information and involvement in treatment decisions: elderly cancer patients' preferences and their physicians' perceptions. J Clin Oncol. 2007;25(33):5275-5280.

98. Smith SG, Wolf MS, Obichere A, Raine R, Wardle J, von Wagner C. The development and testing of a brief ('gist-based') supplementary colorectal cancer screening information leaflet. Patient Educ Couns. 2013;93(3):619-625.

99. van Agt HM, Korfage IJ, Essink-Bot M-L. Interventions to enhance informed choices among invitees of screening programmes-a systematic review. Eur J Public Health. 2014;24(5):789-801.

100. Saini SD, van Hees F, Vijan S. Smarter screening for cancer: possibilities and challenges of personalization. JAMA. 2014;312(21):2211-2212.

101. Oxentenko AS, Goel NK, Pardi DS, et al. Colorectal cancer screening education, prioritization, and self-perceived preparedness among primary care residents: data from a national survey. J Cancer Educ. 2007;22(4):208-218.

102. Ferrari Bravo M, De Conca V, Devoto GL, et al. Colorectal cancer screening in LHU4 Chiavarese, Italy: ethical, methodological and outcome evaluations at the end of the first round. J Prev Med Hyg. 2012;53(1):37-43.

103. Lane DS, Cavanagh MF, Messina CR, Anderson JC. An academic medical center model for community colorectal cancer screening: the Centers for Disease Control and Prevention demonstration program experience. Acad Med. 2010;85(8):1354-1361.

104. Coebergh JW. Challenges and pitfalls of mass-screening in the European union. Eur J Cancer. 2000;36(12):1469-1472.

105. Senore C, Malila N, Minozzi S, Armaroli P. How to enhance physician and public acceptance and utilisation of colon cancer screening recommendations. Baillieres Best Pract Res Clin Gastroenterol. 2010;24(4):509-520.

106. Liles EG, Schneider JL, Feldstein AC, et al. Implementation challenges and successes of a population-based colorectal cancer screening program: a qualitative study of stakeholder perspectives. Implement Sci. 2015;10:41.

107. Levin B. Implementation of colorectal cancer screening: the challenge. Curr. 2002;18(1):82-86.

108. Haug U, Rosch T, Hoffmeister M, Katalinic A, Brenner H, Becker N. Implementing an organised colorectal cancer screening programme in germany: opportunities and challenges. Gesundheitswesen. 2015;77(11):869-874.

109. Rubin DT, Ulitsky A, Poston J, Day R, Huo D. What is the most effective way to communicate results after endoscopy? Gastrointest Endosc. 2007;66(1):108-112.

110. Nawaz AA, Gregory DH. Colorectal cancer screening challenges health professionals. Am J Gastroenterol. 2000;95(10):2992-2993.

111. Robb KA, Power E, Kralj-Hans I, Atkin WS, Wardle J. The impact of individually-tailored lifestyle advice in the colorectal cancer screening context: a randomised pilot study in North-West London. Prev Med. 2010;51(6):505-508.

112. Sunkara V, Hebert JR. The colorectal cancer mortality-to-incidence ratio as an indicator of global cancer screening and care. Cancer. 2015;121(10):1563-1569.

113. Berkowitz SA, Percac-Lima S, Ashburner JM, et al. Building equity improvement into quality improvement: reducing socioeconomic disparities in colorectal cancer screening as part of population health management. J Gen Intern Med. 2014;29:S42-S43.

114. Berkowitz SA, Percac-Lima S, Ashburner JM, et al. Building equity improvement into quality improvement: reducing socioeconomic disparities in colorectal cancer screening as part of population health management. J Gen Intern Med. 2015;30(7):942-949.

115. Ward PR, Javanparast S, Matt MA, et al. Equity of colorectal cancer screening: cross-sectional analysis of National Bowel Cancer Screening Program data for South Australia. Aust N Z J Public Health. 2011;35(1):61-65.

116. Ward PR, Javanparast S, Wilson C. Equity of colorectal cancer screening: which groups have inequitable participation and what can we do about it? Aust J Prim Health. 2011;17(4):334-346.

117. Javanparast $S$, Ward $P$, Young G, et al. How equitable are colorectal cancer screening programs which include FOBTs? A review of qualitative and quantitative studies. Prev Med. 2010;50(4):165-172.

118. Hurtado JL, Bacigalupe A, Calvo M, et al. Social inequalities in a population based colorectal cancer screening programme in the Basque Country. BMC Public Health. 2015;15:1021.

119. Glanz K, Yackle A. Tackling the burden of cancer in the 21st century: understanding and communicating in new and future contexts. Health Educ Behav. 2015;42(1):5-7.

120. Larsen IK, Grotmol T, Almendingen K, Hoff G. Lifestyle characteristics among participants in a Norwegian colorectal cancer screening trial. Eur J Cancer Prev. 2006;15(1):10-19.

121. Burgess DJ, van Ryn M, Grill J, et al. Presence and correlates of racial disparities in adherence to colorectal cancer screening guidelines. $J$ Gen Intern Med. 2011;26(3):251-258.

122. Bao Y, Fox SA, Escarce JJ. Socioeconomic and racial/ethnic differences in the discussion of cancer screening: "between-" versus "within-" physician differences. Health Serv Res. 2007;42(3 Pt 1): 950-970.

123. Liss DT, Baker DW. Understanding current racial/ethnic disparities in colorectal cancer screening in the United States: the contribution of socioeconomic status and access to care. Am J Prev Med. 2014;46(3):228-236.

124. Palmer CK, Thomas MC, McGregor LM, von Wagner C, Raine R. Understanding low colorectal cancer screening uptake in South Asian faith communities in England-a qualitative study. BMC Public Health. 2015;15:998.

125. Angus J, Seto L, Barry N, et al. Access to cancer screening for women with mobility disabilities. J Cancer Educ. 2012;27(1):75-82.

126. C-j L, Fleck T, Goldfarb J, Green C, Porter E. Attitudes to colorectal cancer screening after reading the prevention information. J Cancer Educ. 2011;26(4):701-707.

127. Codori AM, Petersen GM, Miglioretti DL, et al. Attitudes toward colon cancer gene testing: factors predicting test uptake. Cancer Epidemiol Biomarkers Prev. 1999;8(4 Pt 2):345-351.

128. Azoulay L, Gralnek IM, Provenzale D, Talley J, Griffin JM. Evaluating the Impact of health literacy on knowledge, attitudes, and beliefs toward colorectal cancer ( $\mathrm{crc}$ ) and crc screening in veterans. The value study: veterans as leaders in understanding and education. Gastrointest Endosc. 2012;75(4):346-346.

129. Kaphingst KA, Zanfini CJ, Emmons KM. Accessibility of web sites containing colorectal cancer information to adults with limited literacy (United States). Cancer causes \& control : CCC. 2006;17(2):147-151.

130. Wilson EA, Wolf MS, Curtis LM, et al. Literacy, cognitive ability, and the retention of health-related information about colorectal cancer screening. J Health Commun. 2010;15(Suppl 2):116-125.

131. van der Heide I, Uiters E, Schuit A, Rademakers J, Fransen M. Health literacy and informed decision making regarding colorectal cancer screening: a systematic review. Eur J Public Health. 2015;25(4):575-582.

132. Wong MC, Ching JY, Chan VC, et al. Factors associated with falsepositive and false-negative fecal immunochemical test results for colorectal cancer screening. Gastrointest Endosc. 2015;81(3):596-607.

133. Kadiyala S, Strumpf EC. Are United States and Canadian cancer screening rates consistent with guideline information regarding the 
age of screening initiation? International J Qual Health Care 2011;23(6):611-620.

134. Federici A, Valle S, Rossi PG, Grassi A, Borgia P, Guasticchi G. Colorectal cancer screening: recommendations and guideline adherence by physicians from digestive endoscopy centers in the Lazio region, Italy. Preventive Medicine: An International Journal Devoted to Practice and Theory. 2006;43(3):183-186.

135. Nodora JN, Martz WD, Ashbeck EL, Jacobs ET, Thompson PA Martinez ME. Primary care physician compliance with colorectal cancer screening guidelines. Cancer Causes Control. 2011;22(9):1277-1287.

136. Ransohoff DF, Sox HC. Clinical practice guidelines for colorectal cancer screening: new recommendations and new challenges. JAMA. 2016;315(23):2529-2531.

137. Imperiale TF, Ransohoff DF. Understanding differences in the guidelines for colorectal cancer screening. Gastroenterology. 2010;138(5):1642-U1626.

138. Ubel PA, Jepson C, Baron J, Hershey JC, Asch DA. The influence of cost-effectiveness information on physicians' cancer screening recommendations. Soc Sci Med. 2003;56(8):1727-1736.

139. Ubel PA, Baron J, Nash B, Asch DA. Are preferences for equity over efficiency in health care allocation "all or nothing"? Med Care. 2000;38(4):366-373.

140. Shaukat A, Mongin SJ, Geisser MS, et al. Long-term mortality after screening for colorectal cancer. $N$ Engl J Med. 2013;369(12):1106-1114.

141. Holme O, Schoen RE, Senore C, et al. Mo1710 Effectiveness of flexible sigmoidoscopy screening in men and women. A meta-analysis of three large randomized trials. Gastroenterology. 2016;150(4): S758-S759.

142. Ortiz JJ, Di Palma G, Krause M, et al. Endoscopic findings in the elderly, do they give us a new approach to the age limit for colorecta cancer screening? Gastrointest Endosc. 2016; 1):AB290.

143. Kormos W. On call. I'm 76 and I have had three normal colonoscopies for routine colorectal cancer screening. Am I done now?Harv Mens Health Watch. 2012;17(2):2.

144. Day LW, Velayos F. Colorectal cancer and the elderly. Clin Geriatr Med. 2014;30(1):117-131.

145. Hoffman RM, Walter LC. Colorectal cancer screening in the elderly: the need for informed decision making. J Gen Intern Med. 2009;24(12):1336-1337.

146. Sugrue C, Piggott R, Mahmood A, Khan W, Barry K, Waldron R. Understanding patient predictive factors of inadequate bowel preparation for colonoscopy: an observational prospective study. Ir J Med Sci. 2012;181:S178.

147. Yoong KK, Heymann T. Colonoscopy in the very old: why bother? Postgrad Med J. 2005;81(953):196-197.

148. Day LW, Velayos F. Colorectal cancer screening and surveillance in the elderly: updates and controversies. Gut and liver. 2015;9(2):143-151.

149. Imperiale TF, Monahan PO, Stump TE, Glowinski EA, Ransohoff DF. Derivation and validation of a scoring system to stratify risk for advanced colorectal neoplasia in asymptomatic adults: a cross-sectional study. Ann Intern Med. 2015;163(5):339-346.

150. Sigurdsson JA, Getz L, Sjonell G, Vainiomaki P, Brodersen J. Marginal public health gain of screening for colorectal cancer: modelling study, based on WHO and national databases in the Nordic countries. J Eval Clin Pract. 2013;19(2):400-407.

151. Eaden J, Mayberry MK, Sherr A, Mayberry JF. Screening: the legal view. Public Health. 2001;115(3):218-221.

152. Meyskens FL Jr, Mukhtar H, Rock CL, et al. Cancer prevention: obstacles, challenges and the road ahead. J Natl Cancer Inst. 2016;108(2).

153. Schottenfeld D, Beebe-Dimmer J. Alleviating the burden of cancer: a perspective on advances, challenges, and future directions. Cancer Epidemiol Biomarkers Prev. 2006;15(11):2049-2055.
154. Flitcroft KL, St John DJ, Howard K, et al. A comparative case study of bowel cancer screening in the UK and Australia: evidence lost in translation? J Med Screen. 2011;18(4):193-203.

155. Flitcroft K, Gillespie J, Salkeld G, Carter S, Trevena L. Getting evidence into policy: the need for deliberative strategies? Soc Sci Med. 2011;72(7):1039-1046.

156. Flitcroft KL, Gillespie JA, Carter SM, Trevena LJ, Salkeld GP. When good evidence is not enough: the role of context in bowel cancer screening policy in New Zealand. Evidence \& Policy. 2011;7(3):307-326.

157. Album D, Westin S. Do diseases have a prestige hierarchy? A survey among physicians and medical students. Soc Sci Med. 2008;66(1):182-188.

158. Mukherjee S. The Emperor of All Maladies: A Biography of Cancer. New York: Simon and Schuster; 2010.

159. Levin B, Lieberman DA, McFarland B, et al. Screening and surveillance for the early detection of colorectal cancer and adenomatous polyps, 2008: a joint guideline from the American Cancer Society, the US Multi-Society Task Force on Colorectal Cancer, and the American College of Radiology. CA Cancer J Clin. 2008;58(3):130-160.

160. Rex DK, Ahnen DJ, Baron JA, et al. Serrated lesions of the colorectum: review and recommendations from an expert panel. Am J Gastroenterol. 2012;107(9):1315-1329, quiz 1314, 1330.

161. Holme O, Bretthauer M, Eide TJ, et al. Long-term risk of colorectal cancer in individuals with serrated polyps. Gut. 2015;64(6):929-936.

162. Goodwin JS. Geriatrics and the limits of modern medicine. N Engl J Med. 1999;340(16):1283-1285.

163. Verweij M. Medicalization as a moral problem for preventative medicine. Bioethics. 1999;13(2):89-113.

164. Van der Burg W. The slippery slope argument. Ethics. 1991;102(1):42-65.

165. Holm S, Takala T. High hopes and automatic escalators: a critique of some new arguments in bioethics. J Med Ethics. 2007;33(1):1-4.

166. Gaddam S, Jacobson BC, Wani S, Das A, Early DS. Colorectal cancer screening (crcs) legislation alone is inadequate in decreasing cancer incidence: surveillance, epidemiology, and end results (seer) registry analysis. Gastroenterology. 2015;148(4):S753-S754.

167. DeGroff A, Boehm J, Goode Green S, Holden D, Seeff LC. Facilitators and challenges to start-up of the colorectal cancer screening demonstration program. Prev Chronic Dis. 2008;5(2):A39.

168. Haas M, Hall J, Viney R, Gallego G. Breaking up is hard to do: why disinvestment in medical technology is harder than investment. Australian health review : a publication of the Australian Hospital Association. 2012;36(2):148-152.

169. Henshall C, Schuller T, Mardhani-Bayne L. Using health technology assessment to support optimal use of technologies in current practice: the challenge of "disinvestment". Int J Technol Assess Health Care. 2012;28(3):203-210

170. Penston J. Should we use total mortality rather than cancer specific mortality to judge cancer screening programmes? YesBMJ (Clinical research ed). 2011;343:d6395.

171. Steele RJ, Brewster DH. Should we use total mortality rather than cancer specific mortality to judge cancer screening programmes? No. BMJ (Clinical research ed.). 2011;343:d6397.

172. Assasi N, Schwartz L, Tarride JE, Campbell K, Goeree R. Methodological guidance documents for evaluation of ethical considerations in health technology assessment: a systematic review. Expert Rev Pharmacoecon Outcomes Res. 2014;14(2):203-220.

173. Ustun C, Ceber E. Ethical issues for cancer screening. Asian Pac J Cancer Prev. 2003;4(4):373-376 
How to cite this article: Hofmann, B. (2016), Ethical issues with colorectal cancer screening-a systematic review, J Eval Clin Pract, doi: 10.1111/jep.12690

\section{APPENDIX A}

\section{Appendix: search strategy Ethics in CRC screening}

Performed by Ingvild Kirkehei, Norwegian Institute for Public Health, Oslo

Performed: June 24, 2016

\section{Databases}

MEDLINE, Embase, PsycINFO, PubMed Bioethics subset, ISI Web of Knowledge, Bioethics Literature Database (BELIT), Ethics in Medicine (ETHMED), SIBIL Base dati di bioetica, LEWI Bibliographic Database on Ethics in the Sciences and Humanities, and EUROETHICS.

\section{Search strategy}

The search strategies were elaborated for each database, because of the differences in content, indexing, and search options.

For the searches in MEDLINE og Embase the same search strategy for "colorectal cancer» and "screening» were applied as for the systematic review by Fretheim et al referred to in the article. The searches resulted in 1120 references, 870 after removing duplicates.

\section{ISI web of knowledge}

References found: 196

\# 4 \#2 OR \#1 Refined by: Databases: (WOS)

\# 3 \#2 OR \#1

\# 2 TITLE: ("colorectal cancer") AND TITLE: ("screening" or "colonoscop*" or "Colonograph" or"sigmoidoscop*" or "ifobt*" or "fobt*" or "occult blood" or "stool*" or "fecal" or "faecal") AND TITLE: ("autonomy" or "self-determination" or "privacy" or "confidentiality" or "authenticity" or "agency" or "dignity" or "integrity" or "self-conception" or "selfness" or "personhood" or "vulnerability" or "medicalization" or "lifestyle" or "human rights" or "norm*" or "priority" or "prioritization" or "equality" or "equity" or "justice" or "religio*" or ("risk*" and "benefi*") or "stakeholder*" or "informed consent" or "understanding" or "voluntariness" or "nudging" or "legal" or "legislation*" or "regulation*" or "false positive*" or "false negative*" or "predictive value*" or "medicalization" or "overdiagnosis" or "over diagnosis" or "overtreatment" or "over treatment*" or "target group*" or "dual use")

\# 1 TOPIC: ("colorectal cancer") AND TOPIC: ("screening" or "colonoscop*" or "Colonograph*" or "sigmoidoscop*" or "ifobt*" or "fobt*" or "occult blood" or "stool*" or "fecal" or "faecal") AND TOPIC: ("ethic*" or "moral*")

\section{MEDLINE (Ovid)}

Epub Ahead of Print, In-Process and Other Nonindexed Citations, Ovid MEDLINE(R) Daily and Ovid MEDLINE(R) 1946 to Present

References found: 407

1. exp Colorectal Neoplasms/ or ((colorectal* or colon*) adj2 (cancer* or neoplasm* or tumor* or carcinoma*)).tw.

2. colonoscopy/ or Colonography, Computed Tomographic/ or sigmoidoscopy/ or Occult Blood/ or exp Biomarkers, Tumor/bl or Immunochemical/ or Mass screening/ or Early Detection of Cancer/ or (colonoscop* or Colonograph* or sigmoidoscop* or ifobt* or fobt* or (occult* adj2 blood*) or stool* or fecal or faecal or (DNA and blood) or (biomarker* adj3 (blood* or tumor* ${ }^{*}$ or molecular)) or screening or screen* for or immunochemic* or immunol*).tw. or detect*.ti.

3. exp Ethics/ or morale/ or morals/ or moral development/ or (ethic* or moral* or challenges).tw.

4. (autonomy or self-determination or privacy or confidentiality or authenticity or agency or dignity or integrity or self-conception or selfness or personhood or vulnerability or medicalization or lifestyle or human rights or norm* or value* or priority or prioritization or equality or equity or justice or religio* or (risk* and benefi*) or safety or stakeholder or information or informed or understanding or voluntariness or nudging or bias or legal or legislation* or regulation* or guideline* or false positive* or false negative* or predictive value* or medicalization or overdiagnosis or over diagnosis or overtreatment or over treatment* or target group* or subgroup* or "dual use").tw

5. personal autonomy/ or exp Privacy/ or exp Confidentiality/ or personhood/ or exp Self Concept/ or Medicalization/ or Life Style/ or exp Human Rights/ or Social Norms/ or Social Values/ or Health Priorities/ or Health Equity/ or social justice/ or exp Religion/ or Risk Assessment/ or exp Safety/ or exp Access to Information/ or exp Consumer Health Information/ or Informed Consent/ or awareness/ or comprehension/ or consciousness/ or exp "bias (epidemiology)"/ or legal cases/ or legislation/ or social control, formal/ or government regulation/ or exp guideline/ or Guideline Adherence/ or exp Diagnostic Errors/ or "Predictive Value of Tests"/ or exp Medical Overuse/

\section{6. or/4-5}

7. 1 and 2 and 3 and 6

8. exp *Ethics/ or *morale/ or *morals/ or *moral development/ or (ethic* or moral* or challeng*).ti.

\section{1 and 2 and 8}

10. 7 or 9

11. (colorectal cancer and screening and (autonomy or selfdetermination or privacy or confidentiality or authenticity or agency or dignity or integrity or self-conception or selfness or personhood or vulnerability or medicalization or lifestyle* or human rights or norm* or social value* or priority or prioritization or equality or equity or justice or religio* or (risk* and benefi*) or stakeholder or informed consent or understanding or voluntariness or nudging or legal or legislation* or regulation* or false positive* or false negative* or predictive value* or medicalization or overdiagnosis or over diagnosis or overtreatment or over treatment* or target group* or "dual use")).ti.

13. 10 or 11 


\section{EMBASE (Ovid)}

\section{0 to 2016 Week 25}

References found: 159

1. (((colorectal* or colon*) adj2 (cancer* or neoplasm* or tumor* or carcinoma*)) and (colonoscop* or Colonograph* or sigmoidoscop* or ifobt* or fobt* or (occult* adj2 blood*) or stool* or fecal or faecal or DNA or immunol* or immunochem* or DNA* or (biomarker* adj3 (blood* or tumor*)) or screening or screen* for)).tw.

2. (ethic* or moral*).mp.

3. (autonomy or self-determination or privacy or confidentiality or authenticity or agency or dignity or integrity or self-conception or selfness or personhood or vulnerability or medicalization or lifestyle or human rights or norm* or value* or priority or prioritization or equality or equity or justice or religio* or (risk* and benefi*) or safety or stakeholder or information or informed or understanding or voluntariness or nudging or bias or legal or legislation* or regulation* or guideline* or false positive* or false negative* or predictive value* or medicalization or overdiagnosis or over diagnosis or overtreatment or over treatment* or target group* or subgroup* or "dual use").mp.

\section{1 and 2 and 3}

5. (ethic* or moral*).ti. or *ethics/ or *bioethics/ or *ethical theory/ or exp *medical ethics/ or *research ethics/ or *morality/
6. 1 and 5
7. 4 or 6
8. limit 7 to embase

\section{PsycINFO (Ovid)}

\section{6 to June Week 32016}

References found: 134

1. ((colorectal* or colon*) adj2 (cancer* or neoplasm* or tumor* or carcinoma*)).tw.

2. (colonoscop* or Colonograph* or sigmoidoscop* or ifobt* or fobt* or (occult* adj2 blood*) or stool* or fecal or faecal or (DNA and blood) or (biomarker* adj3 (blood* or tumor* or molecular)) or screening or screen* for or immunochemic* or immunol*).tw. or detect*.ti.

3. exp CANCER SCREENING/ or exp SCREENING/ or exp SCREENING TESTS/

4. 2 or 3

5. 1 and 4

6. exp ethics/

7. morality/ or dignity/ or integrity/ or exp justice/ or moral development/ or personal values/ or exp religious beliefs/ or social values/ or exp values/ or virtue/

8. (ethic* or moral*).tw.

9. (autonomy or self-determination or privacy or confidentiality or authenticity or agency or dignity or integrity or self-conception or selfness or personhood or vulnerability or medicalization or lifestyle or human rights or norm* or value* or priority or prioritization or equality or equity or justice or religio* or (risk* and benefi*) or safety or stakeholder or information or informed or understanding or voluntariness or nudging or bias or legal or legislation* or regulation* or guideline* or false positive* or false negative* or predictive value* or medicalization or overdiagnosis or over diagnosis or overtreatment or over treatment* or target group* or subgroup* or "dual use").ti.

10. 6 or 7 or 8 or 9

11. 5 and 10

\section{PubMed Bioethics subset}

References found: 156

("colorectal cancer" OR "colon cancer") AND screening AND bioethics [sb] AND (autonomy or "self-determination" or privacy or confidentiality or authenticity or agency or dignity or integrity or "self-conception" or selfness or personhood or vulnerability or medicalization or lifestyle or "human rights" or norm* or value* or priority or prioritization or equality or equity or justice or religio* or (risk* and benefi*) or safety or stakeholder or information or informed or understanding or voluntariness or nudging or bias or legal or legislation* or regulation* or guideline* or "false positive" or "false negative" or predictive value* or medicalization or overdiagnosis or overtreatment or target group* or subgroup* or "dual use")

\section{BELIT-Bioethics Literature Database}

Searched via http://www.drze.de/belit-1/belit?set_language=en

References found: 57

Advanced search

Everywhere: «colorectal cancer»

Everywhere: screening

Combined with AND

\section{ETHMED-Ethics in Medicine}

Searched via http://www.idem.uni-goettingen.de/en/ethmed.html

References found: 3

Search 1: rectal AND cancer AND screening

Search 2: colorectal AND cancer AND screening

\section{SIBIL-Base dati di bioetica}

Searched via http://www.iss.it/site/SebinaOpac_sedo/Opac?locale= en_GB

References found: 0

Search 1: Word search: colorectal cancer AND screening

Search 2: Word search: cancer AND screening

\section{LEWI-Bibliographic Database on Ethics in the Sciences and Humanities}

Searched via http://lewi.izew.uni-tuebingen.de/lewi/assoziativ_en. html

References found: 7

Quick search: cancer screening

\section{EuroEthics}

Searched via EthicsWeb http://www.ethicsweb.eu/node/1

Search 1: "colorectal cancer" AND screening

No new findings beyond PubMed.

Search 2: «Colon cancer» AND screening

1 new finding beyond PubMed 


\section{Author Query Form}

\section{Journal: Journal of Evaluation in Clinical Practice}

\section{Article: jep_12690}

Dear Author,

During the copyediting of your paper, the following queries arose. Please respond to these by annotating your proofs with the necessary changes/additions.

- If you intend to annotate your proof electronically, please refer to the E-annotation guidelines.

- If you intend to annotate your proof by means of hard-copy mark-up, please use the standard proofing marks. If manually writing corrections on your proof and returning it by fax, do not write too close to the edge of the paper. Please remember that illegible mark-ups may delay publication.

Whether you opt for hard-copy or electronic annotation of your proofs, we recommend that you provide additional clarification of answers to queries by entering your answers on the query sheet, in addition to the text mark-up.

\begin{tabular}{|c|l|c|}
\hline Query No. & \multicolumn{1}{|c|}{ Query } \\
\hline Q1 & $\begin{array}{l}\text { AUTHOR: Please confirm that given names (red) and surnames/family names (green) } \\
\text { have been identified correctly. }\end{array}$ \\
\hline Q2 & AUTHOR: Please supply country for this affiliation. & Remark \\
\hline Q3 & AUTHOR: Please check that author's affiliation is correct. \\
\hline Q4 & $\begin{array}{l}\text { AUTHOR: Please check all section headings if these are presented in their appropriate } \\
\text { section levels. }\end{array}$ & AUTHOR: Please check Figure 1 caption if it is presented correctly. \\
\hline Q6 & $\begin{array}{l}\text { AUTHOR: Please check this website address and confirm that it is correct. } \\
\text { AUTHOR: Please note that this proof exceeds the journal's free pages allocation (7pp) } \\
\text { and will be subject to a charge for excess pages. Where papers extend beyond 7 journal } \\
\text { pages they will incur a charge of £60GBP per extra page. You have the following } \\
\text { options? Remove/edit content from your proof in order to make it 7pp or less; Pay } \\
\text { excess page charges when the article is published in an issue of the journal. }\end{array}$ \\
\hline
\end{tabular}


Required software to e-Annotate PDFs: Adobe Acrobat Professional or Adobe Reader (version 7.0 or above). (Note that this document uses screenshots from Adobe Reader $\mathrm{X}$ )

The latest version of Acrobat Reader can be downloaded for free at: http://get.adobe.com/uk/reader/

Once you have Acrobat Reader open on your computer, click on the Comment tab at the right of the toolbar:

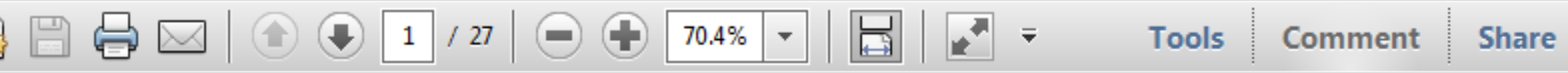

This will open up a panel down the right side of the document. The majority of tools you will use for annotating your proof will be in the Annotations section, pictured opposite. We've picked out some of these tools below:

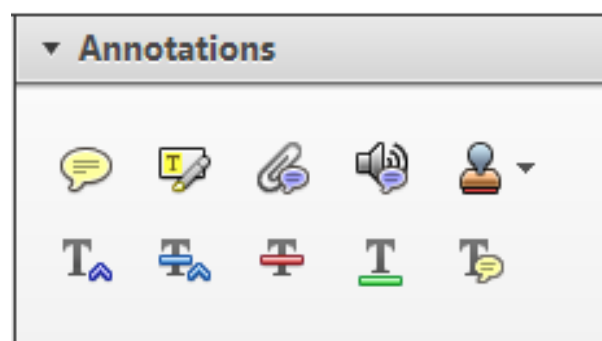

1. Replace (Ins) Tool - for replacing text.

Strikes a line through text and opens up a text box where replacement text can be entered.

How to use it

- Highlight a word or sentence.

- Click on the Replace (Ins) icon in the Annotations section.

- Type the replacement text into the blue box that appears.

Idard tramework for the analysis of $\mathrm{m}$ icy-Nevertheless, it also led to exog،

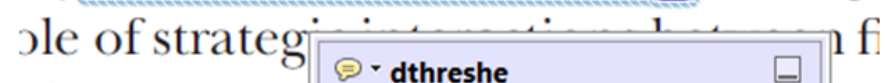
aber of comp 08/06/2011 15:58:17 is that the s1 nain compo: be level, are exc nc


M heneferth) ${ }^{1}$ we anen the "hlarl $\mathrm{l}$

3. Add note to text Tool - for highlighting a section to be changed to bold or italic.

T Highlights text in yellow and opens up a text box where comments can be entered.

\section{How to use it}

- Highlight the relevant section of text.

- Click on the Add note to text icon in the Annotations section.

- Type instruction on what should be changed regarding the text into the yellow box that appears.

namic responses of mark ups ent with the VAR evidence

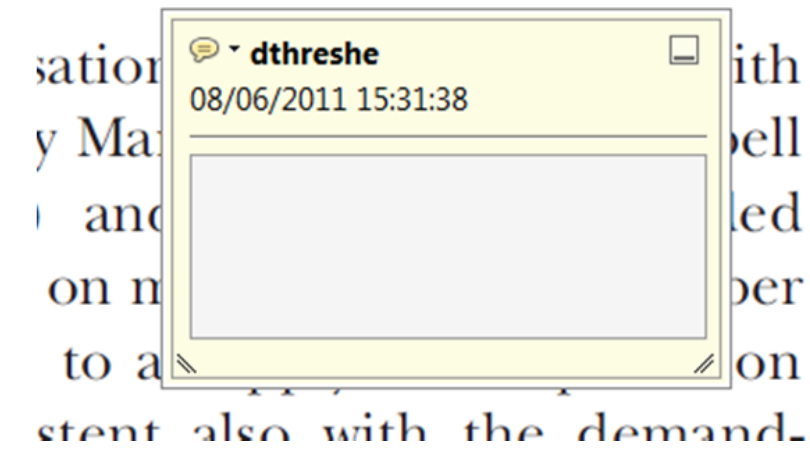

2. Strikethrough (Del) Tool - for deleting text.



Strikes a red line through text that is to be deleted.

How to use it

- Highlight a word or sentence.

- Click on the Strikethrough (Del) icon in the Annotations section.

there is no room tor extra prohts al c ups are zero and the number of ret) values are not determined by Blanchard and Kiyotaki (1987), sfect competition in general equilil ts of aggregate demand and supply lassical framework assuming monol eph on evorenous number of firme

4. Add sticky note Tool - for making notes at specific points in the text.

Marks a point in the proof where a comment needs to be highlighted.

How to use it

- Click on the Add sticky note icon in the Annotations section.

- Click at the point in the proof where the comment should be inserted.

- Type the comment into the yellow box that appears.

iaisu airu suppiy sirucks. hivsl ui

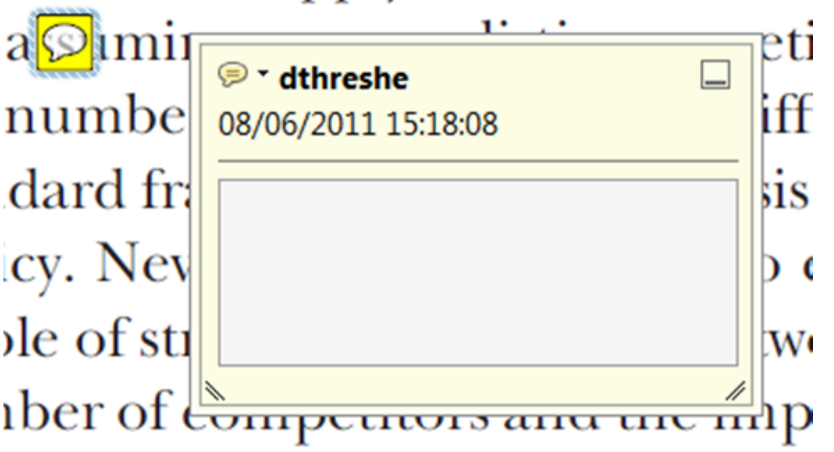

is that the structure of the secto. 
5. Attach File Tool - for inserting large amounts of text or replacement figures.

Inserts an icon linking to the attached file in the appropriate pace in the text.

How to use it

- Click on the Attach File icon in the Annotations section.

- Click on the proof to where you'd like the attached file to be linked.

- Select the file to be attached from your computer or network.

- Select the colour and type of icon that will appear in the proof. Click OK.

E N D



6. Add stamp Tool - for approving a proof if no corrections are required.

- Inserts a selected stamp onto an appropriate place in the proof.

\section{How to use it}

- Click on the Add stamp icon in the Annotations section.

- $\quad$ Select the stamp you want to use. (The Approved stamp is usually available directly in the menu that appears).

- Click on the proof where you'd like the stamp to appear. (Where a proof is to be approved as it is, this would normally be on the first page).

or the business cycie, starting with the on perfect competition, constant ret

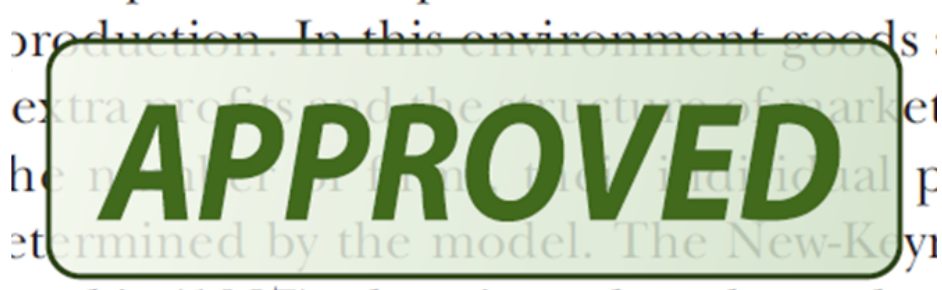
otaki (1987), has introduced produc general equilibrium models with nomin:



- Drawing Markups

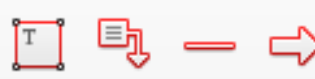

$0 \bigcirc \sqrt{6} \otimes$

\section{How to use it}

- Click on one of the shapes in the Drawing Markups section.

- Click on the proof at the relevant point and draw the selected shape with the cursor.

- To add a comment to the drawn shape, move the cursor over the shape until an arrowhead appears.

- Double click on the shape and type any text in the red box that appears.
7. Drawing Markups Tools - for drawing shapes, lines and freeform annotations on proofs and commenting on these marks.

Allows shapes, lines and freeform annotations to be drawn on proofs and for comment to be made on these marks.



For further information on how to annotate proofs, click on the Help menu to reveal a list of further options:

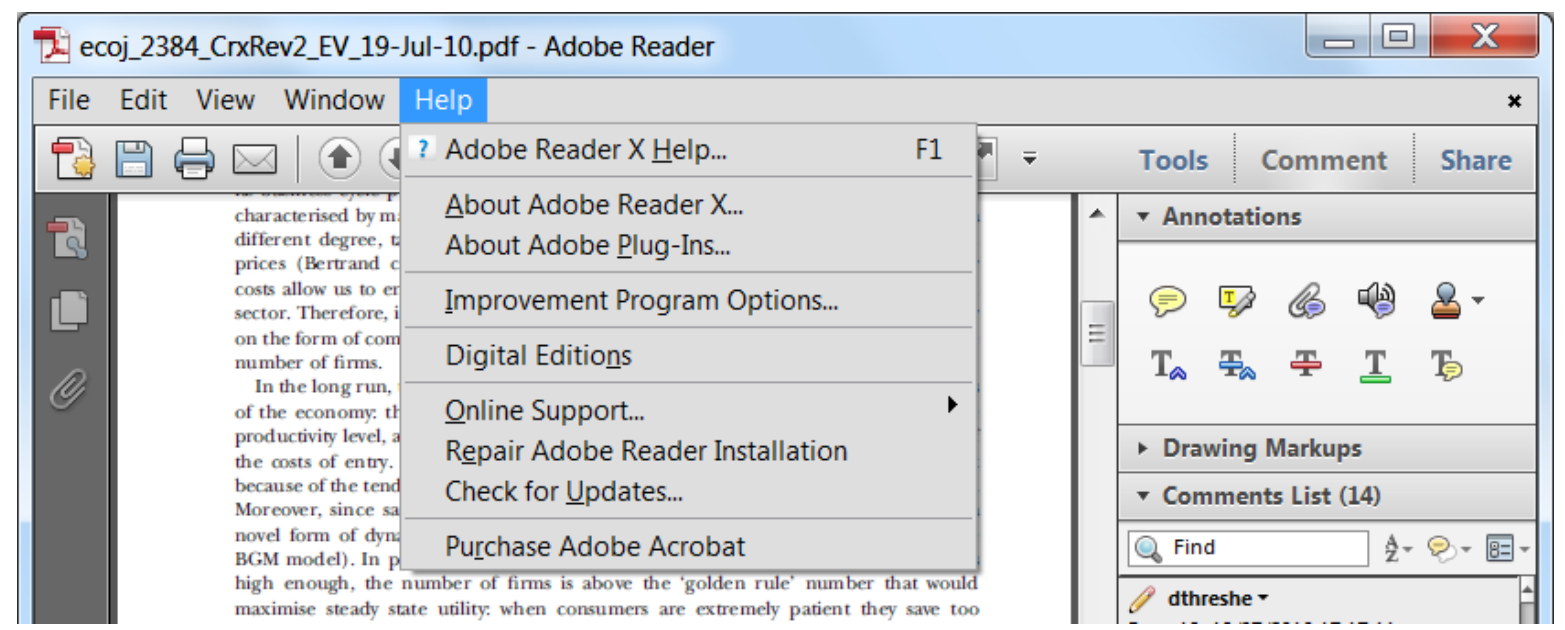

